\title{
openheart Transcatheter versus surgical aortic valve replacement: a systematic review and meta-analysis of randomised and non-randomised trials
}

\author{
Vinayak Nagaraja, ${ }^{1,3}$ Jwalant Raval, ${ }^{2}$ Guy D Eslick, ${ }^{3}$ Andrew T L Ong ${ }^{4}$
}

To cite: Nagaraja V, Raval J, Eslick GD, et al. Transcatheter versus surgical aortic valve replacement: a systematic review and meta-analysis of randomised and nonrandomised trials. Open Heart 2014;: : 000013

doi:10.1136/openhrt-2013000013

- Additional material is available. To view please visit the journal online (http://dx. doi.org/10.1136/openhrt2013-000013)

Received 5 December 2013 Revised 26 May 2014 Accepted 15 July 2014

CrossMark

\begin{abstract}
${ }^{1}$ Prince of Wales Clinical School, University of New South Wales, Prince of Wales Hospital, Australia

${ }^{2}$ Department of Cardiology, Blacktown Hospital, Australia ${ }^{3}$ The Whiteley-Martin Research Centre, Discipline of Surgery, The University of Sydney, Nepean Hospital, Sydney, NSW, Australia ${ }^{4}$ Department of Cardiology, Blacktown Hospital, Australia
\end{abstract}

Correspondence to Guy D Eslick;

guy.eslick@sydney.edu.au

\section{ABSTRACT}

Introduction: Many patients deemed inoperable for surgical aortic valve replacement (SAVR) have been treated successfully by transcatheter aortic-valve replacement (TAVR). This meta-analysis is designed to evaluate the performance of TAVR in comparison with SAVR.

Methods: A systematic search was conducted using MEDLINE, PubMed, EMBASE, Current Contents Connect, the Cochrane library, Google Scholar, Science Direct and Web of Science. Original data were abstracted from each study and used to calculate a pooled OR and $95 \% \mathrm{Cl}$.

Results: Among three randomised controlled trials (RCTs), differences between the two cohorts were not statistically significant for the frequency of stroke ( $\mathrm{OR}=1.94,95 \% \mathrm{Cl}=0.813$ to 4.633 ), incidence of myocardial infarction (MI), (OR=0.765, $95 \% \mathrm{Cl}=0.05$ to 11.76) 30 -day mortality rate, 1 -year mortality rate $(0.82,95 \% \mathrm{Cl}=0.62$ to 1.09$)$ and acute kidney injury incidence rate. The non-RCTs demonstrated that the TAVR group had an amplified frequency aortic regurgitation at discharge $(\mathrm{OR}=5.465,95 \% \mathrm{Cl}=3.441$ to 8.680). While differences between the two cohorts were not statistically significant for the incidence of $\mathrm{MI}$ ( $\mathrm{OR}=0.697,95 \% \mathrm{Cl}=0.22$ to 2.21 ), stroke (OR=0.575, $95 \% \mathrm{Cl}=0.263$ to 1.259 ), acute renal failure requiring haemodialysis ( $\mathrm{OR}=0.943,95 \% \mathrm{Cl}=0.276$ to 3.222 ), 30-day mortality ( $\mathrm{OR}=0.869,95 \% \mathrm{Cl}=0.621$ to 1.216 ) and the need for a pacemaker ( $O R=1.832,95 \%$ $\mathrm{Cl}=0.869$ to 3.862 ), a lower incidence of patients needing transfusion $(\mathrm{OR}=0.349,95 \% \mathrm{Cl}=0.121$ to $1.005)$ and new-onset atrial fibrillation $(\mathrm{OR}=0.296$, $95 \% \mathrm{Cl}=0.124$ to 0.706 ) was seen in the TAVR group.

Conclusions: Randomised and observational evidence adjusted on the baseline patient's characteristics finds a similar risk for 30 days mortality, 1-year mortality, stroke, MI and acute kidney injury in TAVR and SAVR.

\section{INTRODUCTION}

Surgical aortic valve replacement (SAVR) is the gold standard for treating aortic valve stenosis in operable patients. ${ }^{1}$ Even though SAVR improves symptoms and survival, ${ }^{2-4}$ subgroups of patients are at increased risk

\section{KEY MESSAGES}

What is already known about this subject?

- Severe symptomatic aortic stenosis carries a poor prognosis and aortic valve replacement is the mainstay of treatment.

What does this study add?

- This study is a comprehensive review of the evidence published so far and concludes TAVR was noninferior to surgical therapy at 30 days and 1 year.

How might this impact on clinical practice?

- In properly selected patients, TAVR offers substantial improvements in symptoms and life expectancy.

for mortality and morbidity and it would be desirable for this cohort to undergo a less invasive procedure. Transcatheter AVR (TAVR) can be performed by the transfemoral (TF) or transapical route. ${ }^{5-7}$ Results of recent randomised prospective trials demonstrate both the future promise and current problems of the TAVR approach. The PARTNER Trial Investigators ${ }^{8-12}$ have shown that patients with aortic stenosis (AS) who are high risk developed complications with conventional surgery, SAVR and TAVR have similar mortality at 30 days and 1 year and lead to comparable improvements in symptoms. Transcatheter replacement could be a substitute for surgical replacement in the high-risk subgroup of patients with AS. The purpose of the study was to compare the efficacy and safety end points of TAVR with SAVR through a meta-analysis and review the evidence published so far.

\section{METHODS}

\section{Study protocol}

We followed the Preferred Reporting Items for Systematic reviews and Meta-Analyses 
(PRISMA) guidelines where possible in performing our systematic review. ${ }^{13}$ We performed a systematic search through MEDLINE (from 1950), PubMed (from 1946), EMBASE (from 1949), Current Contents Connect (from 1998), the Cochrane library, Google scholar, Science Direct and Web of Science until May 2014. The search terms included "trans-catheter aortic valve implantation, percutaneous aortic valve implantation, percutaneous aortic valve replacement, transfemoral aortic valve implantation, transapical aortic valve implantation, transarterial aortic valve implantation, direct aortic valve implantation, transcatheter aortic-valve replacement (TAVR)", safety end points (stroke, myocardial infarction, atrial fibrillation, major vascular complications, acute kidney injury, blood transfusion), aortic valve stenosis (AS) AND "surgical aortic valve replacement (SAVR)", which were searched as text word and as exploded medical subject headings where possible. No language restrictions were used in either the search or study selection. The reference lists of relevant articles were also searched for appropriate studies. A search for unpublished literature was not performed. The search was conducted by two researchers (VN and JR).

\section{Study selection}

We included studies that met the following inclusion criteria:

- Studies identifying the population of patients with AS.

- Randomised and non-randomised trials comparing TAVR and SAVR.

- Original data (or ORs) reporting on the number of patients who underwent TAVR/SAVR stratified by various patient characteristics/outcomes/safety end points (stroke, myocardial infarction (MI), atrial fibrillation (AF), major vascular complications, acute kidney injury, blood transfusion).

\section{Quality of the studies}

Two independent reviewers screened the studies for inclusion, extracted data and evaluated quality ( $\mathrm{VN}$ and JR). Quality assessment of randomised controlled trials (RCTs) was performed by the two reviewers according to the Cochrane Handbook for Systematic Reviews of Interventions V.5.1.0 based on the following aspects: random sequence generation, blinding of participants and personnel, blinding of outcome assessment, incomplete outcome data, selective reporting and other sources of bias. Three bias levels including low risk, high risk and unclear were assigned to every study aspect. Studies with more 'low-risk' bias assignations were recognised as superior. For non-random controlled studies, a modification of the Newcastle-Ottawa Scale (NOS) was used as an assessment tool for selection, comparability and outcome assessment. ${ }^{14}$ Study quality was rated on a scale from 1 (very poor) to 9 (high). Disagreements were resolved by consensus. This has been summarised in online supplementary table $\mathrm{S} 1$ and table 1.

\section{Data extraction}

The full texts of the studies were read and data extraction was conducted by two independent reviewers (VN and JR). We performed data extraction using a standardised data extraction form, collecting information on the publication year, study design, number of cases, total sample size, population type, country, continent, mean age and clinical data. The event rate and CIs were calculated.

\section{Data synthesis and analysis}

Among non-randomised trials, a subgroup analysis was performed for the statistically sound studies (propensity score matched studies, case matched studies and adjusted analysis) to attain robust results. In order to assess the performance of the transapical approach with SAVR, a subgroup analysis was also performed. A subgroup analysis for the TF group and other approaches for TAVR were not possible due to the lack of extractable information from the studies.

\section{Statistical analysis}

Pooled event rate and 95\% CIs were calculated using a random effects model (DerSimonian and Laird). ${ }^{15}$ We tested heterogeneity with Cochran's $Q$ statistic, with $\mathrm{p}<0.10$ indicating heterogeneity, and quantified the degree of heterogeneity using the $\mathrm{I}^{2}$ statistic, which represents the percentage of the total variability across studies which is due to heterogeneity. $\mathrm{I}^{2}$ values of $25 \%$, $50 \%$ and $75 \%$ corresponded to low, moderate and high degrees of heterogeneity, respectively. ${ }^{16}$ Publication bias was quantified using Egger's regression model, ${ }^{17}$ with the effect of bias assessed using the fail-safe number

\section{Table 1 Quality assessment}

\begin{tabular}{|c|c|c|c|}
\hline Author & PARTNER trial $^{9}$ & STACCATO trial $^{22}$ & Adams et $a f^{23}$ \\
\hline Random sequence generation & Low & Low & Low \\
\hline Allocation concealment & Low & Low & Low \\
\hline Blinding of participants and personnel & Unclear & Unclear & Unclear \\
\hline Blinding of outcome assessment & Unclear & Unclear & Unclear \\
\hline Incomplete outcome data & Low & Low & Low \\
\hline Selective reporting & Low & Low & Low \\
\hline
\end{tabular}


method. The fail-safe number was the number of studies that we would need to have missed for our observed result to be nullified to statistical non-significance at the $\mathrm{p}<0.05$ level. Publication bias is generally regarded as a matter of concern if the fail-safe number is less than $5 \mathrm{n}$ +10 , with $\mathrm{n}$ being the number of studies included in the meta-analysis. ${ }^{18}$ All analyses were performed with a Comprehensive Meta-analysis (V.2.0).

\section{RESULTS}

The search strategy retrieved 447 studies (figure 1 ). The abstracts were reviewed and after applying the inclusion and exclusion criteria, articles were selected for full-text evaluation. Systematic review ${ }^{19}$ and meta-analyses ${ }^{20} 21$ were excluded. Of the articles selected, only 39 studies (13 130 patients) met the full criteria for analysis and are summarised in online supplementary table S1. Of these, we found 3 RCTs, ${ }^{9} 222310$ propensity score matched studies, ${ }^{24-32} 5$ case matched studies ${ }^{33-37}$ and 2 studies that provided adjusted analysis. ${ }^{38} 39$ The years of publication ranged from 2002 to 2014.

\section{Randomised controlled trials}

Only three RCTs ${ }^{922}$ have been conducted so far and they comprised 1564 patients. The STACCATO trial $^{22}$ compared transapical TAVR with SAVR, whereas the PARTNER trial $^{9}$ and Adams et $a t^{23}$ compared TF and transapical TAVR with SAVR. Data analysis was based on an intention-to-treat approach. Differences between the two cohorts were not statistically significant for the frequency of stroke $(\mathrm{OR}=1.94,95 \% \mathrm{CI}=0.813$ to 4.633$)$, incidence of MI $(\mathrm{OR}=0.765,95 \% \mathrm{CI}=0.05$ to 11.76$), 30$ day mortality rate $(\mathrm{OR}=1.057,95 \% \mathrm{CI}=0.13$ to 8.568$)$, 1-year mortality rate $(\mathrm{OR}=0.82,95 \% \mathrm{CI}=0.62$ to 1.09$)$ and acute kidney injury $(\mathrm{OR}=1.072,95 \% \mathrm{CI}=0.514$ to 2.239$)$ incidence rate. The average overall hospitalisation time was $9.5(\mathrm{SD}=0.99)$ and 12 days $(\mathrm{SD}=6.223)$ in the TAVR and SAVR cohorts, respectively ( $\mathrm{p}$ value $=0.6217$ ). The results have been tabulated in table 2 and illustrated in figures 2-6.

\section{Non-randomised controlled trials}

Crude analysis

A total of 36 studies with 11566 patients were included in the study. The TAVR group had an amplified

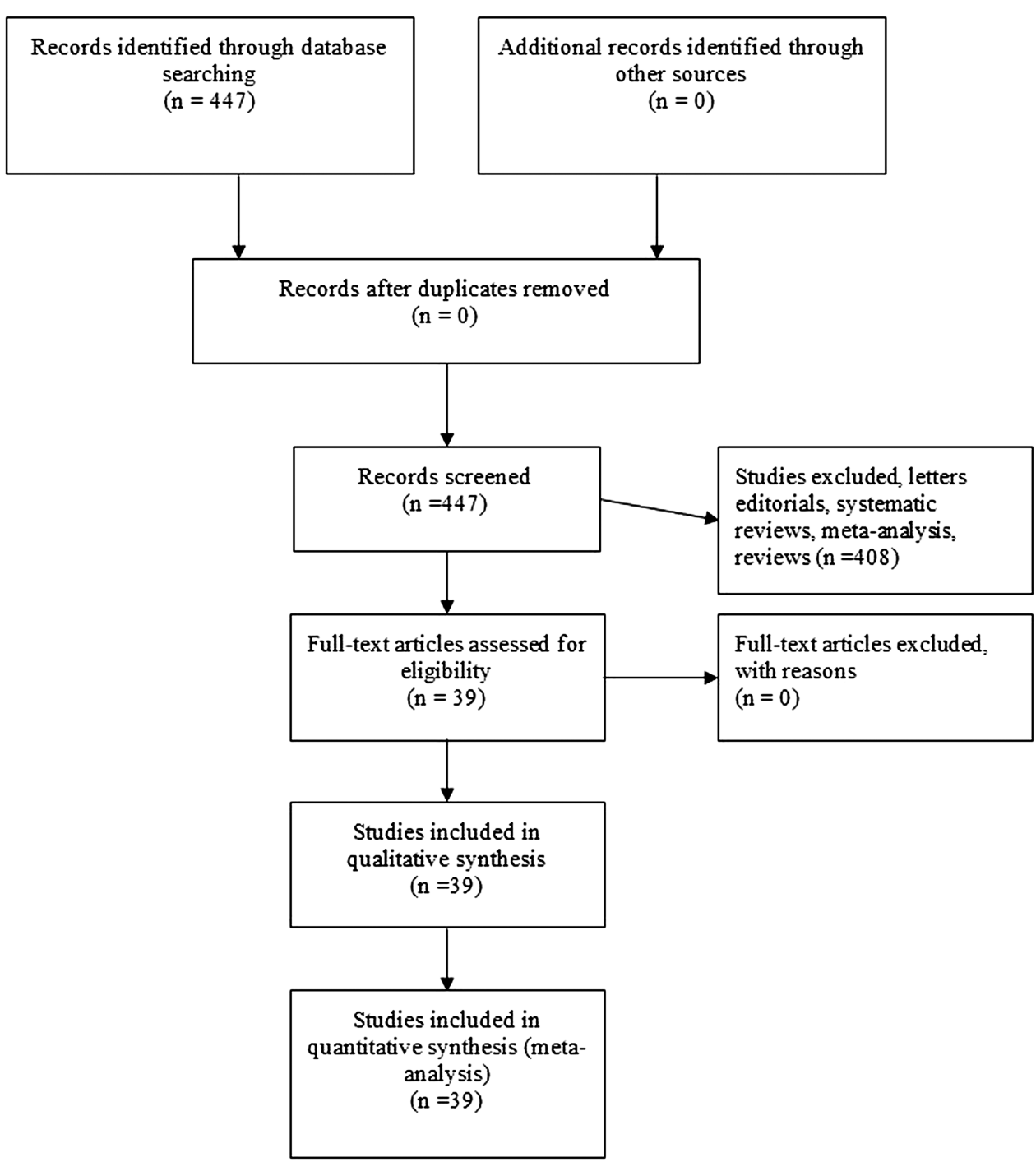

Figure 1 Flow of included studies. 
Table 2 Overall OR and $95 \% \mathrm{Cl}$ for randomised controlled trials

\begin{tabular}{llllllll}
\hline Outcome & $\begin{array}{l}\text { Number of } \\
\text { studies }\end{array}$ & $\begin{array}{l}\text { Total number } \\
\text { of patients }\end{array}$ & OR & 95\% Cl & p Value & $\mathbf{I}^{\mathbf{2}}$ & $\left.\mathbf{p ~ V a l u e ~} \mathbf{I}^{\mathbf{2}}\right)$ \\
\hline 30-day mortality & 2 & 769 & 1.06 & 0.13 to 8.57 & 0.959 & 53.15 & 0.14 \\
1-year mortality & 2 & 1494 & 0.82 & 0.62 to 1.09 & 0.17 & 15.24 & 0.28 \\
Acute kidney injury & 2 & 769 & 1.072 & 0.514 to 2.239 & 0.853 & 0 & 0.48 \\
Myocardial infarction & 2 & 769 & 0.765 & 0.05 to 11.76 & 0.848 & 34.14 & 0.21 \\
Stroke & 2 & 769 & 1.940 & 0.813 to 4.633 & 0.135 & 0 & 0.91 \\
\hline
\end{tabular}

Figure 2 Thirty-day mortality.

\section{0-day mortality}

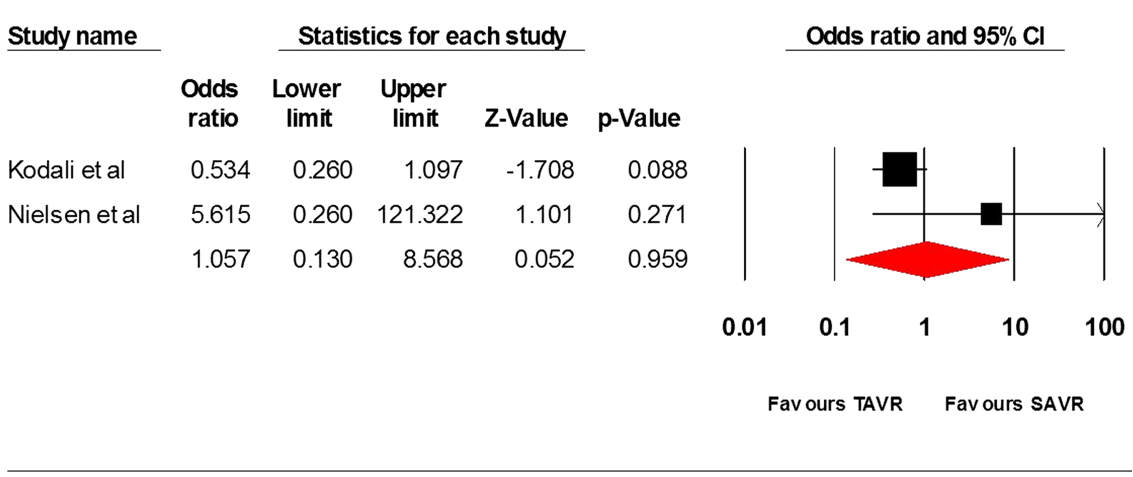

Figure 3 Stroke.

Figure 4 Myocardial infarction.

Myocardial infarction

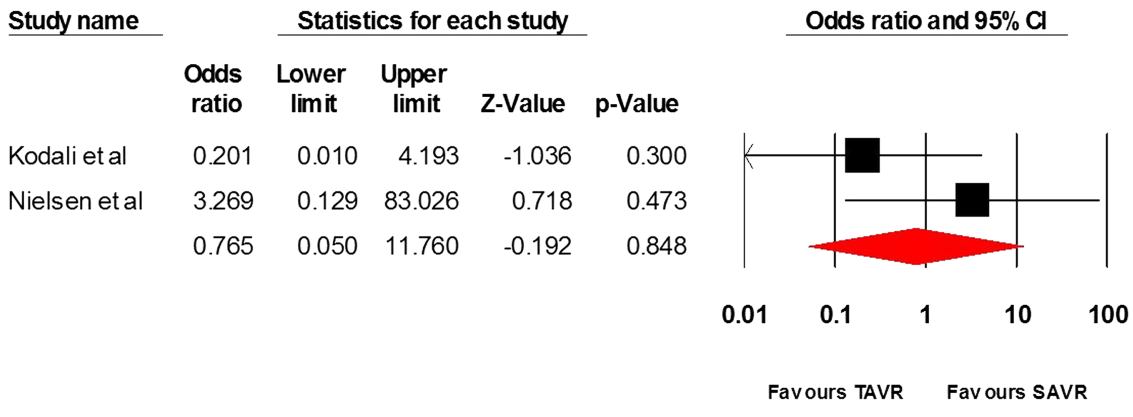


Figure 5 Acute kidney injury.

Acute kidney injury

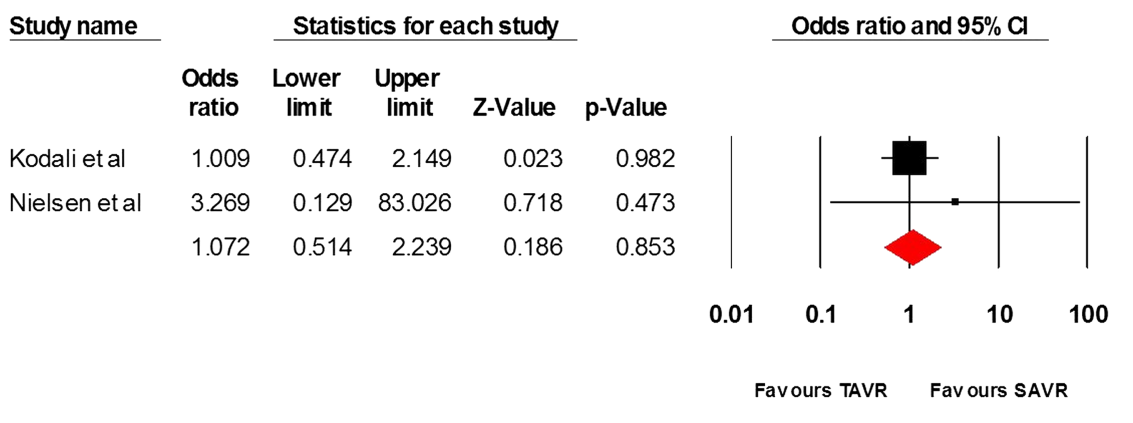

frequency of pacemaker insertion $(\mathrm{OR}=3.169,95 \%$ $\mathrm{CI}=2.338$ to 4.294), a major vascular complication $(\mathrm{OR}=7.117,95 \% \mathrm{CI}=2.287$ to 22.149$)$ and aortic regurgitation at discharge $(\mathrm{OR}=7.412,95 \% \mathrm{CI}=3.695$ to 14.868$)$. While differences between the two cohorts were not statistically significant for the incidence of $\mathrm{MI}(\mathrm{OR}=0.774$, $95 \% \mathrm{CI}=0.338$ to 1.770$)$ and 30 -day mortality $(\mathrm{OR}=1.332$, $95 \% \mathrm{CI}=0.953$ to 1.861 ), a lower incidence of new-onset $\mathrm{AF} \quad(\mathrm{OR}=0.353,95 \% \quad \mathrm{CI}=0.148$ to 0.842$)$, patients needing transfusion $(\mathrm{OR}=0.392,95 \% \mathrm{CI}=0.189$ to 0.812$)$ and patients requiring haemodialysis ( $\mathrm{OR}=0.863,95 \%$ $\mathrm{CI}=0.361$ to 2.063 ) was observed in the TAVR cohort. The average overall hospitalisation time was 10.33 and 12.21 days in the TAVR and SAVR cohorts, respectively $(p$ value $=0.0473)$. The mean duration of stay in intensive care was 2.79 and 3.95 days ( $p$ value $=0.0281$ ) and the operative times were 150 and $215 \mathrm{~min}$ in the TAVR and SAVR groups, respectively ( $\mathrm{p}$ value $=0.0114$ ). The results have been tabulated in online supplementary table S2.

Subgroup analysis of statistically sound studies

We performed a subgroup analysis for propensity score matched studies, ${ }^{24-32}$ case matched studies ${ }^{33-37}$ and studies that provided adjusted analysis. ${ }^{38} 39$ The TAVR group had an amplified frequency aortic regurgitation at discharge $(\mathrm{OR}=5.465,95 \% \mathrm{CI}=3.441$ to 8.680$)$. While differences between the two cohorts were not statistically significant for the incidence of $\mathrm{MI} \quad(\mathrm{OR}=0.697,95 \%$ $\mathrm{CI}=0.22$ to 2.21$)$, stroke $(\mathrm{OR}=0.575,95 \% \mathrm{CI}=0.263$ to $1.259)$, acute renal failure requiring haemodialysis $(\mathrm{OR}=0.943,95 \% \mathrm{CI}=0.276$ to 3.222$)$, 30-day mortality
$(\mathrm{OR}=0.869,95 \% \mathrm{CI}=0.621$ to 1.216$)$ and the need for a pacemaker $(\mathrm{OR}=1.832,95 \% \mathrm{CI}=0.869$ to 3.862$)$, a lower incidence of patients needing transfusion $(\mathrm{OR}=0.349$, $95 \% \mathrm{CI}=0.121$ to 1.005$)$ and new-onset $\mathrm{AF}(\mathrm{OR}=0.296$, $95 \% \mathrm{CI}=0.124$ to 0.706 ) was seen in the TAVR group.

Among these studies, we also performed a subgroup analysis for three statistically sound transapical TAVR versus SAVR studies, ${ }^{27} 2940$ which demonstrated that the differences between the two cohorts were not statistically significant for the incidence of stroke $(\mathrm{OR}=0.196,95 \%$ $\mathrm{CI}=0.023$ to 1.698$)$ and 30 -day mortality $(\mathrm{OR}=0.7,95 \%$ $\mathrm{CI}=0.382$ to 1.282 ). A subgroup analysis for the TF group and other approaches for TAVR were not possible due to the lack of extractable information from the studies.

\section{Heterogeneity and publication bias}

The heterogeneity of outcomes has been summarised in table 2 and online supplementary table S2. No publication bias was detected using Egger's regression model.

\section{DISCUSSION}

In the past 10 years, TAVR has gained popularity in higher risk populations. Many patients deemed inoperable for AVR have been treated successfully by TAVR. According to our meta-analysis, both randomised and observational evidence adjusted on the baseline patient's characteristics find a similar risk for 30-day mortality, stroke, MI and acute kidney injury (AKI) in TAVR and SAVR. TAVR is associated with a lower incidence of patients needing transfusion and new-onset AF.

Figure 6 One-year mortality.

\begin{tabular}{lrrrr} 
Study name & \multicolumn{4}{c}{ Statistics for each study } \\
\cline { 3 - 5 } & $\begin{array}{c}\text { Odds } \\
\text { ratio }\end{array}$ & $\begin{array}{c}\text { Lower } \\
\text { limit }\end{array}$ & $\begin{array}{c}\text { Upper } \\
\text { limit }\end{array}$ & p-Value \\
Kodali et al & 0.94 & 0.66 & 1.32 & 0.71 \\
Adams et al & 0.71 & 0.48 & 1.03 & 0.07 \\
& 0.82 & 0.62 & 1.09 & 0.17
\end{tabular}

\section{Odds ratio and $95 \% \mathrm{Cl}$}

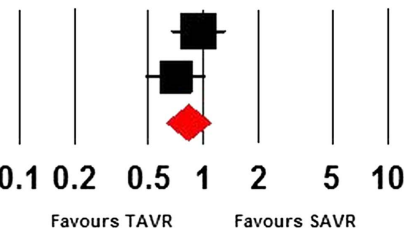




\section{Stroke}

Stroke accounts for a major proportion of mortality post SAVR. This equates to approximately eight times the risk of mortality due to stroke compared to other reasons. ${ }^{41}$ According to the Society of Thoracic Surgeons (STS) database, the overall stroke rate is about $1.5 \% .^{3}{ }^{42}$ After SAVR, stroke with an enduring disability was an imperative predictor of 30-day mortality in geriatric patients. ${ }^{43}$

Most of the participants in these studies were over 80 years and had numerous medical comorbidities accounting for increased risk. The average stroke incidence described in these publications was approximately $4 \% .{ }^{44}$ However, the description of cerebrovascular complications associated with TAVR was inconsistent, which could possibly explain the heterogeneity among the studies. However, the incidence of a cerebrovascular event was more common after TAVR than SAVR in the PARTNER trial equating TAVR and SAVR in high-risk patients. ${ }^{45}$

In our meta-analysis, differences between the two cohorts were not statistically significant for the frequency of stroke $(\mathrm{OR}=1.94,95 \% \mathrm{CI}=0.813$ to 4.633$)$ in the TAVR and SAVR cohorts and no heterogeneity was observed among the two studies.

\section{Need for a permanent pacemaker and post procedural atrial fibrillation}

Owing to the proximity of the infranodal conduction system to the aortic valvular apparatus, patients with AS frequently present with atrioventricular conduction abnormalities (AVCA). In addition, the procedure itself may lead to temporary or permanent injury resulting in AVCA with the need for prolonged monitoring and/or a high rate of permanent pacemaker (PPM) implantation after TAVR. ${ }^{46-50}$ The rates of AVCA reported after SAVR are lower and a PPM is implanted in only 3-4\% of patients undergoing SAVR. ${ }^{51-53}$ Cao et a $e^{54}$ found a 3.5-fold increased risk $(13.2 \%$ vs $3.0 \%$; $\mathrm{p}=0.0003)$ of pacemaker need in patients undergoing TAVR compared to SAVR. Our study presents similar findings;however, the significance was lost on performing a subgroup analysis for statistically sound studies, which was not done by Cao et $a l .{ }^{54}$

Postprocedural AF is a predictor of long-term mortality in patients undergoing cardiac surgery. ${ }^{55}{ }^{56}$ Earlier studies revealed a significant reduction of left atrial pressure in the first postoperative days after aortic valve replacement for aortic stenosis. ${ }^{57} 58$ TAVR allows one to avoid most of the factors causing AF after standard open AVR, such as the inflammatory effect of cardiopulmonary bypass and cardioplegic arrest, part of the postoperative increase of adrenergic tone and pericarditis. ${ }^{59}$ The fact that patients with TAVR experience less periprocedural AF than those receiving AVR is not unexpected. Motloch et $a b^{60}$ reported that the prevalence of post procedural $\mathrm{AF}$ was significantly lower in the TAVR group $(6.0 \%$, vs $33.7 \%$ after SAVR, $\mathrm{p}<0.05)$. A lower incidence of new-onset AF was observed in the TAVR cohort
$(\mathrm{OR}=0.353,95 \% \mathrm{CI}=0.148$ to 0.842$)$ in our analysis, which is consistent with the aforementioned hypothesis.

\section{Acute renal failure and aortic regurgitation}

AKI after cardiac surgery is an autonomous predictor of mortality. ${ }^{61-64}$ Contrast to cholesterol embolisation, hypotension (rapid pacing, balloon valvuloplasty and valve deployment) are risk factors for acute renal failure. In our study, however, the incidence of AKI was similar in both clusters. Patients who underwent TAVR had a higher risk of developing moderate or severe aortic regurgitation, which is inversely related to survival. ${ }^{9}$

\section{Limitations}

\section{Causes for heterogeneity}

Heterogeneity was identified in many of the perioperative results. The classifications of 'high surgical risk' and the risk score models utilised varied between publications. The patient selection criteria for TAVR was diverse between institutes and had mean pressure gradient $\geq 40$ $\mathrm{mm} \mathrm{Hg},{ }^{36}{ }^{38}$ logistic Euroscore $>20 \%{ }^{25} 36{ }^{65}$ or $>15 \%,{ }^{38}$ age $>75^{22} 25406566$ or $>80,{ }^{38}$ aortic valve area of $<1.0^{386768}$ or $<0.8 \mathrm{~cm}^{2},{ }^{9} 4569$ additive Euroscore $\geq 9,{ }^{27} 40$ or STS score $>15 \%$ or $>10 \% .{ }^{945}$ In a few studies, participants who were thought to be 'too high risk' were not offered TAVR, which comprised individuals with EF $<20 \%{ }^{9}{ }^{45}$ or $<15 \%{ }^{66}$ Similarly, crossover treatment was not reported consistently.

In a few studies, there was a considerable loss to follow-up, ${ }^{26}$ exclusion of patients with failed TAVR ${ }^{39}$ and enclosure of participants who had surgical AVR with coronary artery bypass graft or mitral valve surgery. ${ }^{66}$ The follow-up period was short with only three studies providing detailed outcome data beyond 12 months. ${ }^{9} 2338$ The evaluation of effectiveness of TAVR versus AVR in the long term remains unknown and delayed complications have not yet been estimated.

\section{Upcoming clinical trials}

The Nordic Aortic Valve Intervention (NOTION) trial, ${ }^{70}$ PARTNER II trial, MEDTRONIC COREVALVE U.S. PIVOTAL trial, COREVALVE vs SAVR-DENMARK TRIAL and SURTAVI trial are underway or are expected to start aiming to investigate the effectiveness of TAVR in younger and lower risk patients.

\section{CONCLUSION}

TAVR is maturing as a minimally invasive approach for treating patients with severe AS. It is quite agreeable that TAVR today is already preferable in a growing proportion of elderly and fragile patients; however, this procedure has the potential for serious complications. New technology will probably make it worthwhile in a larger proportion of clinical situations. The current evidence and results from this meta-analysis has demonstrated its feasibility and efficacy and drawn the attention of industry and physicians. Although short-term efficacy is good, there is little 
evidence on long-term outcomes. Randomised and observational evidence adjusted on the baseline patient's characteristics finds a similar risk for 30-day mortality, stroke, MI and acute renal injury in TAVR and SAVR. We know that AVR treats the disease quite consistently and is still considered the standard treatment for most patients. The future is expected to be more prosperous as new developments and data from ongoing trials will provide the background to expand TAVR applications and establish their position in a broader spectrum of patients.

Funding This research received no specific grant from any funding agency in the public, commercial or not-for-profit sectors.

Competing interests None.

Provenance and peer review Not commissioned; externally peer reviewed.

Data sharing statement No additional data are available.

Open Access This is an Open Access article distributed in accordance with the Creative Commons Attribution Non Commercial (CC BY-NC 3.0) license, which permits others to distribute, remix, adapt, build upon this work noncommercially, and license their derivative works on different terms, provided the original work is properly cited and the use is non-commercial. See: http:// creativecommons.org/licenses/by-nc/3.0/

\section{REFERENCES}

1. Nishimura RA, Carabello BA, Faxon DP, et al. ACC/AHA 2008 Guideline Update on Valvular Heart Disease: Focused Update on Infective Endocarditis: a Report of the American College of Cardiology/ American Heart Association Task Force on Practice Guidelines: Endorsed by the Society of Cardiovascular Anesthesiologists, Society for Cardiovascular Angiography and Interventions, and Society of Thoracic Surgeons. Circulation 2008;118:887-96.

2. Schwarz F, Baumann P, Manthey J, et al. The effect of aortic valve replacement on survival. Circulation 1982;66:1105-10.

3. O'Brien SM, Shahian DM, Filardo G, et al. The Society of Thoracic Surgeons 2008 cardiac surgery risk models: part 2-isolated valve surgery. Ann Thorac Surg 2009;88:S23-42.

4. Shahian DM, O'Brien SM, Filardo G, et al. The Society of Thoracic Surgeons 2008 cardiac surgery risk models: part 3-valve plus coronary artery bypass grafting surgery. Ann Thorac Surg 2009;88: S43-62.

5. Cribier A, Eltchaninoff $\mathrm{H}$, Bash $\mathrm{A}$, et al. Percutaneous transcatheter implantation of an aortic valve prosthesis for calcific aortic stenosis: first human case description. Circulation 2002:106:3006-8.

6. Cribier A, Eltchaninoff $\mathrm{H}$, Tron $\mathrm{C}$, et al. Treatment of calcific aortic stenosis with the percutaneous heart valve: mid-term follow-up from the initial feasibility studies: the French experience. J Am Coll Cardiol 2006;47:1214-23.

7. Cribier $\mathrm{A}$, Eltchaninoff $\mathrm{H}$, Tron $\mathrm{C}$, et al. Early experience with percutaneous transcatheter implantation of heart valve prosthesis for the treatment of end-stage inoperable patients with calcific aortic stenosis. J Am Coll Cardiol 2004;43:698-703.

8. Genereux P, Webb JG, Svensson LG, et al. Vascular complications after transcatheter aortic valve replacement: insights from the PARTNER (Placement of AoRTic TraNscathetER Valve) trial. J Am Coll Cardiol 2012;60:1043-52.

9. Kodali SK, Williams MR, Smith CR, et al. Two-year outcomes after transcatheter or surgical aortic-valve replacement. N Engl J Med 2012;366:1686-95.

10. Miller DC, Blackstone EH, Mack MJ, et al. Transcatheter (TAVR) versus surgical (AVR) aortic valve replacement: occurrence, hazard, risk factors, and consequences of neurologic events in the PARTNER trial. J Thorac Cardiovasc Surg 2012;143:832-43.

11. Reynolds MR, Magnuson EA, Wang K, et al. Cost-effectiveness of transcatheter aortic valve replacement compared with standard care among inoperable patients with severe aortic stenosis: results from the placement of aortic transcatheter valves (PARTNER) trial (Cohort B). Circulation 2012;125:1102-9.

12. Reynolds MR, Magnuson EA, Wang K, et al. Health-related quality of life after transcatheter or surgical aortic valve replacement in high-risk patients with severe aortic stenosis: results from the PARTNER (Placement of AoRTic TraNscathetER Valve) Trial (Cohort A). J Am Coll Cardiol 2012;60:548-58.
13. Moher D, Liberati A, Tetzlaff J, et al. Preferred reporting items for systematic reviews and meta-analyses: the PRISMA statement. J Clin Epidemiol 2009;62:1006-12.

14. Wells GA, Shea B, O'Connell D, et al. The Newcastle-Ottawa Scale (NOS) for assessing the quality of nonrandomised studies in meta-analyses. http://www.ohri.ca/programs/clinical_epidemiology/ oxford.asp

15. DerSimonian R, Laird N. Meta-analysis in clinical trials. Control Clin Trials 1986;7:177-88.

16. Higgins JP, Thompson SG, Deeks JJ, et al. Measuring inconsistency in meta-analyses. BMJ 2003:327:557-60.

17. Egger M, Smith GD, Schneider M, et al. Bias in meta-analysis detected by a simple, graphical test. BMJ 1997;315:629-34.

18. Orwin R. A fail-safe $\mathrm{N}$ for effect size in meta-analysis. J Educ Stat 1983;8:157-9.

19. Yan TD, Cao C, Martens-Nielsen J, et al. Transcatheter aortic valve implantation for high-risk patients with severe aortic stenosis: a systematic review. J Thorac Cardiovasc Surg 2010;139:1519-28.

20. Généreux P, Head SJ, Van Mieghem NM, et al. Clinical outcomes after transcatheter aortic valve replacement using valve academic research consortium definitions: a weighted meta-analysis of 3,519 patients from 16 studies. J Am Coll Cardiol 2012;59:2317-26.

21. Jilaihawi $\mathrm{H}$, Chakravarty $\mathrm{T}$, Weiss RE, et al. Meta-analysis of complications in aortic valve replacement: comparison of MedtronicCorevalve, Edwards-Sapien and surgical aortic valve replacement in 8,536 patients. Catheter Cardiovasc Interv 2012;80:128-38.

22. Nielsen $\mathrm{HH}$, Klaaborg $\mathrm{KE}$, Nissen $\mathrm{H}$, et al. A prospective, randomised trial of transapical transcatheter aortic valve implantation vs. surgical aortic valve replacement in operable elderly patients with aortic stenosis: the STACCATO trial. Eurolntervention 2012;8:383-9.

23. Adams DH, Popma JJ, Reardon MJ, et al. Transcatheter aortic-valve replacement with a self-expanding prosthesis. $N$ Engl J Med 2014;370:1790-8

24. D'Onofrio A, Messina A, Lorusso R, et al. Sutureless aortic valve replacement as an alternative treatment for patients belonging to the "gray zone" between transcatheter aortic valve implantation and conventional surgery: a propensity-matched, multicenter analysis. $J$ Thorac Cardiovasc Surg 2012;144:1010-16.

25. Conradi L, Seiffert M, Treede $\mathrm{H}$, et al. Transcatheter aortic valve implantation versus surgical aortic valve replacement: a propensity score analysis in patients at high surgical risk. $J$ Thorac Cardiovasc Surg 2012;143:64-71.

26. D'Errigo P, Barbanti M, Ranucci M, et al. Transcatheter aortic valve implantation versus surgical aortic valve replacement for severe aortic stenosis: Results from an intermediate risk propensity-matched population of the Italian OBSERVANT study. Int $J$ Cardiol 2012;25:25.

27. Walther T, Schuler G, Borger MA, et al. Transapical aortic valve implantation in 100 consecutive patients: comparison to propensity-matched conventional aortic valve replacement. Eur Heart J 2010;31:1398-403.

28. Fusari M, Bona V, Muratori M, et al. Transcatheter vs. surgical aortic valve replacement: a retrospective analysis assessing clinical effectiveness and safety. J Cardiovasc Med 2012; 13:229-41.

29. Higgins $\mathrm{J}, \mathrm{Ye} \mathrm{J}$, Humphries $\mathrm{KH}$, et al. Early clinical outcomes after transapical aortic valve implantation: a propensity-matched comparison with conventional aortic valve replacement. J Thorac Cardiovasc Surg 2011;142:e47-52.

30. Latib A, Maisano F, Bertoldi L, et al. Transcatheter vs surgical aortic valve replacement in intermediate-surgical-risk patients with aortic stenosis: a propensity score-matched case-control study. Am Heart $J$ 2012;164:910-17.

31. Osnabrugge RL, Head SJ, Genders TS, et al. Costs of transcatheter versus surgical aortic valve replacement in intermediate-risk patients. Ann Thorac Surg 2012;94:1954-60.

32. Piazza N, van Gameren M, Jüni $P$, et al. A comparison of patient characteristics and 30-day mortality outcomes after transcatheter aortic valve implantation and surgical aortic valve replacement for the treatment of aortic stenosis: a two-centre study. Eurolntervention 2009;5:580-8.

33. Appel CF, Hultkvist $\mathrm{H}$, Nylander $\mathrm{E}$, et al. Transcatheter versus surgical treatment for aortic stenosis: patient selection and early outcome. Scand Cardiovasc J 2012:46:301-7.

34. Guarracino F, Talini E, Landoni G, et al. Effect of aortic valve surgery on left ventricular diastole assessed by echocardiography and neuroendocrine response: percutaneous versus surgical approach. J Cardiothorac Vasc Anesth 2010;24:25-9.

35. Bagur R, Rodés-Cabau J, Gurvitch R, et al. Need for permanent pacemaker as a complication of transcatheter aortic valve implantation and surgical aortic valve replacement in elderly patients 
with severe aortic stenosis and similar baseline electrocardiographic findings. JACC Cardiovasc Interv 2012;5:540-51.

36. Stohr R, Dohmen G, Herpertz R, et al. Thirty-day outcome after transcatheter aortic valve implantation compared with surgical valve replacement in patients with high-risk aortic stenosis: a matched comparison. Coron Artery Dis 2011;22:595-600.

37. Forsberg LM, Tamas E, Vanky F, et al. Left and right ventricular function in aortic stenosis patients 8 weeks post-transcatheter aortic valve implantation or surgical aortic valve replacement. Eur $J$ Echocardiogr 2011;12:603-11.

38. Wenaweser P, Pilgrim T, Kadner A, et al. Clinical outcomes of patients with severe aortic stenosis at increased surgical risk according to treatment modality. J Am Coll Cardiol 2011:58:2151-62.

39. Tamburino C, Barbanti M, Capodanno D, et al. Comparison of complications and outcomes to one year of transcatheter aortic valve implantation versus surgical aortic valve replacement in patients with severe aortic stenosis. Am J Cardiol 2012;109:1487-93.

40. Holzhey DM, Shi W, Rastan A, et al. Transapical versus conventional aortic valve replacement-a propensity-matched comparison. Heart Surg Forum 2012;15:20111084.

41. Filsoufi F, Rahmanian PB, Castillo JG, et al. Incidence, imaging analysis, and early and late outcomes of stroke after cardiac valve operation. Am J Cardiol 2008;101:1472-8.

42. Taylor NE, O'Brien S, Edwards FH, et al. Relationship between race and mortality and morbidity after valve replacement surgery. Circulation 2005;111:1305-12.

43. Melby SJ, Zierer A, Kaiser SP, et al. Aortic valve replacement in octogenarians: risk factors for early and late mortality. Ann Thoracic Surg 2007;83:1651-7.

44. Hynes BG, Rodés-Cabau J. Transcatheter aortic valve implantation and cerebrovascular events: the current state of the art. Ann N Y Acad Sci 2012;1254:151-63.

45. Smith $\mathrm{CR}$, Leon MB, Mack MJ, et al. Transcatheter versus surgical aortic-valve replacement in high-risk patients. $N$ Engl J Med 2011;364:2187-98.

46. Roten L, Stortecky S, Scarcia F, et al. Atrioventricular conduction after transcatheter aortic valve implantation and surgical aortic valve replacement. J Cardiovasc Electrophysiol 2012;23:1115-22.

47. Erkapic D, De Rosa S, Kelava A, et al. Risk for permanent pacemaker after transcatheter aortic valve implantation: a comprehensive analysis of the literature. J Cardiovasc Electrophysiol 2012;23:391-7.

48. Ussia GP, Scarabelli M, Mulè M, et al. Postprocedural management of patients after transcatheter aortic valve implantation procedure with self-expanding bioprosthesis. Catheter Cardiovasc Interv 2010;76:757-66.

49. Sinhal A, Altwegg L, Pasupati S, et al. Atrioventricular block after transcatheter balloon expandable aortic valve implantation. JACC Cardiovasc Interv 2008;1:305-9.

50. Piazza N, Onuma Y, Jesserun E, et al. Early and persistent intraventricular conduction abnormalities and requirements for pacemaking after percutaneous replacement of the aortic valve. JACC Cardiovasc Interv 2008;1:310-16.

51. Limongelli G, Ducceschi V, D'Andrea A, et al. Risk factors for pacemaker implantation following aortic valve replacement: a single centre experience. Heart 2003;89:901-4.

52. Gilbert T, Orr W, Banning AP. Surgery for aortic stenosis in severely symptomatic patients older than 80 years: experience in a single UK centre. Heart 1999;82:138-42.
53. Erdogan HB, Kayalar N, Ardal H, et al. Risk factors for requirement of permanent pacemaker implantation after aortic valve replacement. J Card Surg 2006;21:211-15.

54. Cao C, Ang SC, Indraratna $\mathrm{P}$, et al. Systematic review and meta-analysis of transcatheter aortic valve implantation versus surgical aortic valve replacement for severe aortic stenosis. Ann Cardiothorac Surg 2013;2:10-23.

55. Villareal RP, Hariharan R, Liu BC, et al. Postoperative atrial fibrillation and mortality after coronary artery bypass surgery. J Am Coll Cardiol 2004;43:742-8.

56. Filardo G, Hamilton C, Hamman B, et al. New-onset postoperative atrial fibrillation and long-term survival after aortic valve replacement surgery. Ann Thorac Surg 2010;90:474-9.

57. Carlens $P$. Central haemodynamics in the immediate postoperative period after aortic valve replacement. Scand J Thorac Cardiovasc Surg 1977;11:187-93.

58. Bristow JD, Kremkau EL. Hemodynamic changes after valve replacement with Starr-Edwards prostheses. Am J Cardiol 1975;35:716-24.

59. Benussi S, Cioni M, Alfieri O. Invited commentary. Ann Thorac Surg 2012:93:131-2.

60. Motloch LJ, Reda S, Rottlaender D, et al. Postprocedural atrial fibrillation after transcatheter aortic valve implantation versus surgical aortic valve replacement. Ann Thorac Surg 2012;93: 124-31.

61. Karkouti K, Wijeysundera DN, Yau TM, et al. Acute kidney injury after cardiac surgery: focus on modifiable risk factors. Circulation 2009;119:495-502.

62. Loef BG, Epema AH, Smilde TD, et al. Immediate postoperative renal function deterioration in cardiac surgical patients predicts in-hospital mortality and long-term survival. J Am Soc Nephrol 2005;16:195-200.

63. Chertow GM, Levy EM, Hammermeister KE, et al. Independen association between acute renal failure and mortality following cardiac surgery. Am J Med 1998;104:343-8.

64. Rosner MH, Okusa MD. Acute kidney injury associated with cardiac surgery. Clin J Am Soc Nephrol 2006;1:19-32.

65. Zierer A, Wimmer-Greinecker G, Martens S, et al. Is transapica aortic valve implantation really less invasive than minimally invasive aortic valve replacement? J Thorac Cardiovasc Surg 2009;138:1067-72.

66. De Carlo M, Giannini C, Ettori F, et al. Impact of treatment choice on the outcome of patients proposed for transcatheter aortic valve implantation. Eurolntervention 2010;6:568-74

67. Clavel MA, Webb JG, Rodes-Cabau J, et al. Comparison between transcatheter and surgical prosthetic valve implantation in patients with severe aortic stenosis and reduced left ventricular ejection fraction. Circulation 2010;122:1928-36.

68. Amonn K, Stortecky S, Brinks H, et al. Quality of life in high-risk patients: comparison of transcatheter aortic valve implantation with surgical aortic valve replacement. Eur J Cardiothorac Surg 2013;43:34-42.

69. Stortecky S, Brinks H, Wenaweser P, et al. Transcatheter aortic valve implantation or surgical aortic valve replacement as redo procedure after prior coronary artery bypass grafting. Ann Thorac Surg 2011;92:1324-30.

70. Thyregod HG, Søndergaard L, Ihlemann N, et al. The Nordic Aortic Valve Intervention (NOTION) trial comparing transcatheter versus surgical valve implantation: study protocol for a randomised controlled trial. Trials 2013;14:1745-6215. 